\title{
Multiple Cerebral and Cerebellar Infarctions following Russell's Viper (Daboia Russelii) Envenomation - A Case Report
}

\author{
UDN Prasad ${ }^{1}$ (D) JMRP Bandara ${ }^{2}$ iD and HMS Senanayake ${ }^{2^{*}}$ (iD) \\ ${ }^{1}$ Registrar, Professorial Medical Unit, Teaching Hospital Anuradhapura, Sri Lanka \\ ${ }^{2}$ Consultant Physician, Professorial Medical Unit, Teaching Hospital Anuradhapura, Sri Lanka
}

*Corresponding author: Hemal Senanayake, Consultant Physician, Professorial Medical Unit, Teaching Hospital Anuradhapura, Sri Lanka

\begin{abstract}
Ischemic stroke is a rare neurological complication following SriLankan Russell's viper envenomation. We report a case of a 44-year-old person, who developed multiple cerebral and cerebellar infarctions following SriLankan Russell's viper envenomation. The patient developed both local and systemic envenomation and was treated with Snake Venom Anti-Serum I.P. (VinsBioproducts Ltd). On day six, this patient developed left-sided hemiparesis. CT scan of the brain showed bilateral cerebellar, bilateral occipital, and right-sideparietal lobe infarctions.
\end{abstract}

\section{Keywords}

Cerebral infarctions, Cerebellar infarctions, Russell's viper, Snake bite

\section{Introduction}

There are about 37,000 admissions to Sri Lankan hospitals following snake bites every year [1]. The Sri Lankan Russell's viper is responsible for $30-40 \%$ of these cases. Severe envenomation and case fatalities due to Russell's viper bites are higher compared to other snake bites in Sri Lanka. These viper bites usually occur in paddy (rice) fields and on footpaths at dusk and dawn. It affects agriculture workers and considered to be an occupational hazard in Sri Lanka [1]. Envenomation causes local swelling, coagulopathy, acute kidney injury, neuromuscular paralysis characterized by ophthalmoplegia and ptosis, and rarely respiratory muscle paralysis [1]. Rhabdomyolysis, chronic renal failure, myocardial infarction, and secondary hypopituitarism [1] have also been reported following Russell's viper envenomation.

\section{Case Report}

Anuradhapura is an ancient city in the north-central province of Sri Lanka and is home to around 860,575 people (census 2012). Majorities are farmers and at risk of snakebite. We report a case of a 44-year-old previously healthy farmer from Anuradhapura presenting to the emergency department 90 minutes following a snake bite. Dead snake was identified by the medical officer at the emergency department as Russell's viper (Daboia Russelii -Thith Polanga). There was moderate pain and swelling at the bite site and fang marks were clearly seen on the right foot. Two hours after admission patient developed irritability, vomiting, blurred vision, ptosis, ophthalmoplegia, and, difficulty in breathing with inspiratory stridor \& difficulty in swallowing. His GCS was 15/15; pupils were $3 \mathrm{~mm}$ in size and reacting equally bilaterally. The pulse rate was $80 / \mathrm{min}$, and the blood pressure was $120 / 80 \mathrm{mmHg}$. His oxygen saturation was $100 \%$, and the lungs were clear. He was treated with anti-venom serum (AVS) 20 vials. Six hours after completion of AVS, his whole blood clotting time (WBCT 20) was still prolonged (> 20 minutes) and clotting time was 12 minutes, INR was 2.06; APTT was 56 second (control $44 \mathrm{Sec}$ ). Ten vials of AVS were repeated uneventfully. On day two, the patient developed respiratory distress with worsening inspiratory stridor and the patient was intubated and admitted to ICU. During intubation, severe laryngeal edema and bleeding were noted. During the ICU stay, he developed acute kidney injury with a raised serum creatinine of $193 \mu \mathrm{mol} / \mathrm{dl}$,

Citation: Prasad UDN, Bandara JMRP, Senanayake HMS (2020) Multiple Cerebral and Cerebellar Infarctions following Russell's Viper (Daboia Russelii) Envenomation - A Case Report. Clin Med Rev Case Rep 7:313. doi.org/10.23937/2378-3656/1410313

Accepted: June 11, 2020: Published: June 13, 2020

Copyright: (c) 2020 Prasad UDN, et al. This is an open-access article distributed under the terms of the Creative Commons Attribution License, which permits unrestricted use, distribution, and reproduction in any medium, provided the original author and source are credited. 


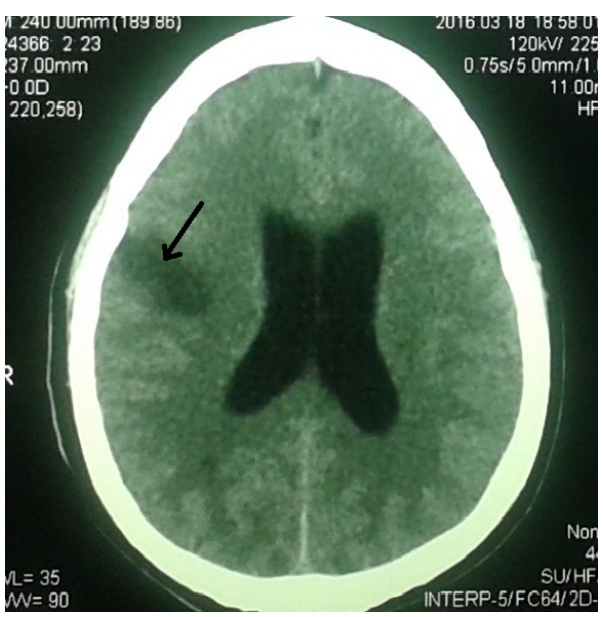

A

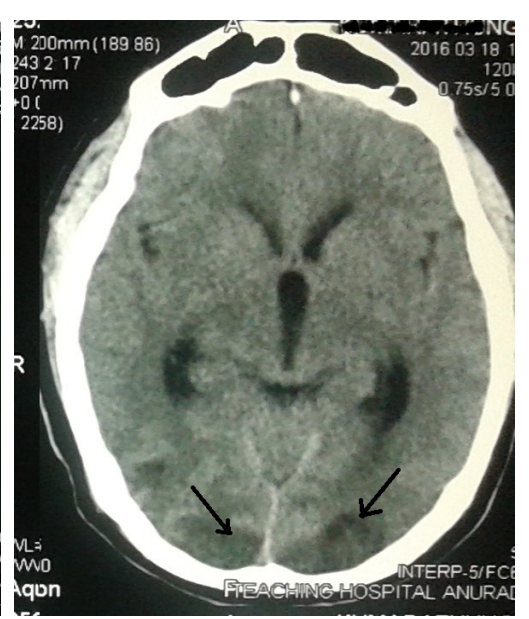

B

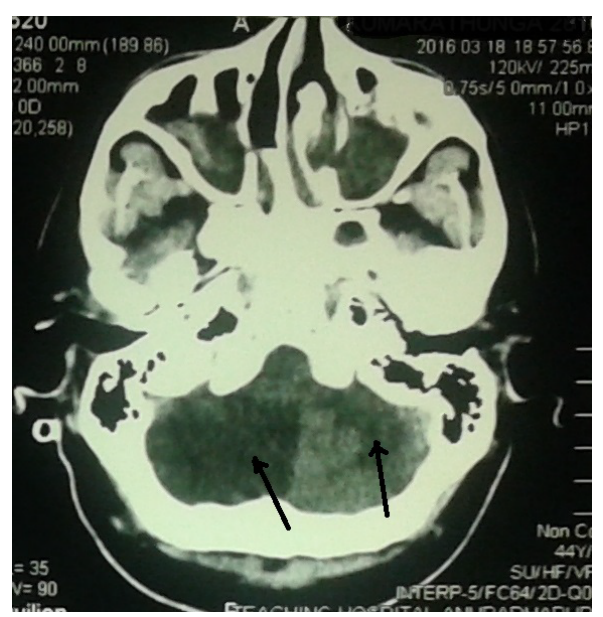

C

Figure 1: Non-enhanced CT brain scan of the patient with infarctions (arrows), involving both anterior and posterior circulation territories. a) Right parietal lobe; b) Bilateral occipital lobes; c) Bilateral cerebellar hemispheres.

Table 1: Previously published cases of ischemic strokes following Russell's viper bites in Sri Lanka.

\begin{tabular}{|l|l|}
\hline Cases of ischemic strokes & Location of Stroke \\
\hline Ameratunga B (1972) [2] & Middle cerebral artery territory \\
\hline Gawarmmana I, et al. [3] & $\begin{array}{l}\text { 1. Cerebellum, Bilateral frontal, and parietal lobes } \\
\text { 2. Right deep parietal and lentiform nucleus } \\
\text { 3. Right frontal and Right cerebellum }\end{array}$ \\
& $\begin{array}{l}\text { 4. Left caudate and bilateral occipital lobes } \\
\text { 5. Left and Right middle cerebral artery territory and bilateral occipital lobes }\end{array}$ \\
& $\begin{array}{l}\text { 6. Multiple bilateral cortical and cerebellum } \\
\text { 7. Left frontal lobe }\end{array}$ \\
\hline 8ubasinghe, et al. [4] & 9. Right parietal and temporal lobes. \\
\hline Rathnayaka RMMKN, et al. [5] & Bilateral occipital infarcts \\
\hline
\end{tabular}

which recovered gradually during the next few days. Throughout his blood pressure remained stable and no cardiac arrhythmias noted. His 2D-echocardiogram was normal. On day six, it was noted that he had developed left-sided hemiparesis. Non-contrast CT of the brain was done and showed right parietal, bilateral occipital and bilateral cerebellar infarctions (Figure 1a, Figure $1 b$ and Figure $1 c$ ) with early obstructive hydrocephalus and cerebral edema. No hemorrhages or midline shift was seen. The neurosurgical team suggested an urgent decompressive craniotomy. Unfortunately, the patient passed away before the procedure.

\section{Discussion}

Although cerebral infarctions were reported following Russell's viper envenomation, infarctions involving both anterior and posterior circulation are rarely reported. Most reported cases had anterior circulation strokes. The following are the few reported cases of ischemic strokes following Russell's viper bite, found in the Sir Lankan literature (Table 1). Russell's viper venom-associated thrombosis involving the heart and limbs is a well-recognized phenomenon [3,6].

The following mechanisms have been proposed as the cause for thrombosis resulting in ischemic cerebral infarction after Russell's viper envenomation. Toxins such as hemorrhagins of snake venom cause vessel wall damage and severe vascular spasm and microthrombi formation $[7,8]$. The toxins with well-established pro-coagulant and platelet aggregating properties like cerastobin [9], factor IVa [10], cerastocytin [11,12], cerastotin [13] and afaacytin [14], causes thrombus formation. Arginine, esterase, and hydrolases in venom also have procoagulant properties [8]. These various protein products have thrombin-like enzyme activity; each toxin activates different pathways of the coagulation cascade. Their activities are inhibited by monoclonal antibodies against GP1b or GPIIb/IIla or thrombin receptor. Endothelial damage, toxin-induced vasculitis $[6,15]$ and, increased vascular permeability may contribute to vascular occlusion leading to thrombosis. Micro-thrombi formation as a sequel to the low-grade disseminated intravascular coagulopathy and hypotension are also leading causes for ischemia and infarction.

Venom induced consumption coagulopathy (VICC) happens following Russell's viper envenomation. It includes a broad range of factor deficiencies depending 
on the procoagulant toxin in the venom, which used to cause bleeding [16].

Better outcomes have been reported with immediate AVS treatment. A large number of studies have demonstrated that antivenom can bind to procoagulant toxins and prevent their effects in vitro if the antivenom and venom are pre-mixed. Antivenom may not be effective in certain situations. The most important being that irreversible toxic effects cannot be reversed by antivenom binding to toxins after the damage has occurred, such as clotting factor deficiencies resulting from VICC. For antivenom to be effective against such irreversible effects, it must be administered early, so it can bind with toxins before they distribute to their target sites and cause irreversible toxicity [15]. But no studies to show the effectiveness of AVS for snakebite-associated thrombotic microangiopathy. The mean time for the onset of stroke symptoms after envenomation seems to be as early as $23.8 \pm 10.9$ hours in some studies [17]. In our patient onset time was much delayed.

In this patientm ischemic infarctions due to hypotensionis unlikely as he was normotensive and no watershed infarctions seen in CT brain. The possibility of a cardiac source of embolization was excluded. His blood picture did not show any evidence of thrombotic microangiopathy. Therefore, it can be hypothesized that toxin-induced vasculitis, pro-coagulant, and platelet aggregating properties of toxins might have given rise to this complication.

\section{Conclusion}

Despite early treatment with AVS, this patient developed cerebral infarctions involving both anterior and posterior circulation territories. This case study illustrates that ischemic cerebral infarctions must be looked in to as a complication related to Russel's viper envenomation. Further research is needed to identify the possible mechanisms of ischemic stroke in the context of snake bites and to develop specific treatment strategies.

\section{Acknowledgments}

No funding was provided for this report.

\section{Conflicts of Interest}

All authors declare no conflicts of interest.

\section{References}

1. Kularatne SA (2003) Epidemiology and clinical picture of the Russell's viper (Daboia russeliirusselii) bite in Anuradhapura, Sri Lanka: A prospective study of 336 cases. Southeast Asian J Trop Med Public Health 34: 855-862.

2. Ameratunga B (1972) Middle cerebral occlusion following Russel's viper bite. J Trop Med Hyg 75: 95-97.

3. Gawarammana I, S Mendis, K Jeganathan (2009) Acute ischemic strokes due to bites by Daboia russelii in Sri Lanka-first authenticated case series. Toxicon 54: 421-428.

4. Subasinghe CJ, Sarathchandra C, Kandeepan T, Kulatun- ga A (2014) Bilateral blindness following Russell's viper bite - a rare clinical presentation: A case report. Journal of Medical Case Reports 8: 99.

5. Rathnayaka RMMKN, Ranathunga PEAN (2017) Late-onset of bilateral cerebral infarction following Russell's viper (Daboia russelii) bite. Sri Lankan Journal of Anaesthesiology 25: 35-38.

6. Hung DZ, Wu ML, Deng JF, Yang DY, Lin-Shiau SY (2002) Multiple thrombotic occlusions of vessels after Russell's viper envenoming. Pharmacol Toxicol 91: 106-110.

7. Rajesh M Kumar, Ramesh P Babu, Amit Agrawal (2015) Multiple infarctions involving cerebral and cerebellar hemispheres following viper bite. Journal of Medical Society 29: 51-53.

8. VK Pothukuchi, VR Chepuri, Kalyani Natta, Nagaraju Madigani, Alok Kumar (2018) A rare case report of Russell's viper snakebite with ischemic stroke. Hong Kong Journal of Emergency Medicine 25: 95-97.

9. Farid TM, Tu AT, el-Asmar MF (1990) Effect of cerastobin, a thrombinlike enzyme from Cerastes viper (Egyptian sand snake) venom, on human platelets. Haemostasis 20: 296304.

10. Basheer AR, el-Asmar MF, Soslau G (1995) Characterization of a potent platelet aggregation inducer from Cerastescerastes (Egyptian sand viper) venom. Biochim Biophys Acta 1250: 97-109.

11. Dekhil H, Wasner A, Marrakchi N, Ayed M, Bon C, et al. (2003) Molecular cloning and expression of a functional snake venom serine proteinase, with platelet aggregating activity, from Cerastes viper. Biochemistry 42: 1060910618.

12. Marrakchi N, Barbouche R, Guermazi S, Bon C, el-Ayeb M (1997) Procoagulant and platelet aggregating properties of cerastocytin from Cerastes cerastes venom. Toxicon 35 : 261-272.

13. Marrakchi N, Barbouche R, Guermazi S, Karoui H, Bon C, et al. (1997) Cerastotin, a serine protease from Cerastescerastes venom, with platelet-aggregating and agglutinating properties. Eur J Biochem 247: 121-128.

14. Laraba-Dejabri F, Martin-Eauclaire MF, Mauco G, Marchot $P$ (1995) Afaacytin, an alpha beta-fibrinogenase from Cerastescerastes(horned viper) venom, activates purified factor $X$ and induces serotonin release from human blood platelets. Eur J Biochem 233: 756-765.

15. Narang SK, Paleti S, Azeez Asad MA, Samina T (2009) Acute ischemic infarct in the middle cerebral artery territory following a Russell's viper bite. Neurol India 57: 479-480.

16. Kalana M, Geoffrey K I (2014) Current Treatment for Venom-Induced Consumption Coagulopathy Resulting from Snakebite. PLoS Negl Trop Dis 8: e3220.

17. Mohammed Al-Sadawi, Maliheh Mohamadpour, Angelina Zhyvotovska, Tahir Ahmad, Joshua Schechter, et al. (2019) Cerebrovascular accident and snake envenomation: A Scoping Study. Int J Clin Res Trials 4: 133. 